\title{
Role of Long Noncoding RNA HOTAIR in the Growth and Apoptosis of Osteosarcoma Cell MG-63
}

\author{
Hua Zheng and Jing Min \\ Department of Orthopedics, Yongchuan Hospital, Chongqing Medical University, Chongqing, China \\ Correspondence should be addressed to Jing Min; minjing0524@163.com
}

Received 25 May 2016; Revised 6 July 2016; Accepted 25 July 2016

Academic Editor: Xin-yuan Guan

Copyright (C) 2016 H. Zheng and J. Min. This is an open access article distributed under the Creative Commons Attribution License, which permits unrestricted use, distribution, and reproduction in any medium, provided the original work is properly cited.

\begin{abstract}
This study investigated the function of HOTAIR in the growth and apoptosis of OS MG-63 cell line in vitro and further clarified its mechanism. The expression levels of HOTAIR in OS MG-63 cell line and normal osteoblast hFOB1.19 cell line were determined by RT-PCR, respectively. The growth and apoptosis of MG-63 cells in vitro were investigated by MTT assay and flow cytometry assay after HOTAIR was knocked down with retroviral vector construction. And the expression levels of cell growth and apoptosis related factors TGF- $\beta$, p53, Bcl-2, and TNF- $\alpha$ were determined to clarify the mechanism. We found that HOTAIR was highly expressed in osteosarcoma MG-63 cell line compared with normal osteoblast hFOB1.19 cell line. The proliferation rate was lower and the apoptosis rate was higher significantly in shHOTAIR MG-63 cells than those in EV MG-63 cells. TGF- $\beta$ and Bcl-2 were downregulated significantly when HOTAIR was knocked down. p53 and TNF- $\alpha$ were upregulated significantly when HOTAIR was knocked down. These results indicated that HOTAIR functioned as a carcinogenic lncRNA, which could promote the proliferation and inhibit the apoptosis of MG-63 cells in vitro. HOTAIR could be a potential target for the treatment of osteosarcoma.
\end{abstract}

\section{Introduction}

Osteosarcoma, which derives from primitive bone-forming mesenchymal cells, is a primary malignant tumor of the skeleton. It was characterized by the direct formation of immature bone or osteoid tissue by the tumor cells. Although it accounts for less than $0.5 \%$ of all types of cancer, OS is the most frequent primary malignancy of the bone and occurs mainly in adolescents and young adults [1]. Generally, OS cases mostly occur in the long tubular bones which account for $80 \%$ to $90 \%$ and rarely affected the axial skeleton. Patients with OS suffer from severe pain and soft tissue swelling. Development of sudden and severe pain may lead to gross pathologic fracture, which is an uncommon finding in adult patients. But up to $15 \%$ of paediatric patients present a pathological fracture [2]. Although the mortality and the survival of OS have been greatly improved, the mortality of OS still ranks the third (8.9\%) in all childhood and adolescent cancer deaths behind leukemias (25.5\%) and brain and other nervous-system neoplasms (25.0\%). Mankin et al. reported that the overall 5 -year survival rate for OS was $68 \%$ without a significant gender difference based on 648 patients treated for OS at Massachusetts General Hospital by the orthopedic oncology group in $2004[3,4]$. Thus, studies on the treatment and the pathogenesis of OS have always been hotspots in recent decades.

Long noncoding RNAs (lncRNAs) are a group of transcribed RNA consisting of more than 200 nucleotides and generally poorly conserved. They are noncoding RNAs, and they can regulate gene expression by different mechanisms which still remain unclear $[5,6]$. The role of $\operatorname{lncRNAs}$ is very different from miRNAs as miRNAs mainly play roles in inhibiting gene expression posttranscriptionally while lncRNAs play important roles in epigenetic regulation, transcriptional control, posttranscriptional regulation, and molecular scaffolding via different mechanisms [7]. Studies have shown that lncRNAs play an important role in Xchromosome inactivation, genomic imprinting, subcellular structural organization, telomere and centromere organization, and nuclear trafficking [7-10]. Moreover, studies have indicated that the dysregulation of lncRNAs is associated with various human diseases, including autoimmune diseases, 
neurological disorders, coronary artery diseases, and cancer [11-13].

HOTAIR, one of the well-studied lncRNAs, was localized at human chromosome 12q13 within the antisense strand of the HOXC gene cluster [14]. Since it was discovered by Rinn et al. in 2007, several studies have shown that HOTAIR is a powerful predictor of invasion and metastasis, cell proliferation, pathological development, or drug resistance in various tumors such as non-small cell lung cancer, melanoma, and gastric cancer [15-18]. For OS, HOTAIR was only reported such that overexpression of HOTAIR could promote tumor growth and metastasis in human osteosarcoma [19].

In this study, we aimed to detect the different expression of HOTAIR in OS cell line and normal osteoblast cell line, investigate the effects of HOTAIR knockdown on growth and apoptosis of OS cells in vitro, and further clarify the mechanism of HOTAIR in OS.

\section{Materials and Methods}

2.1. Cell Culture. Human osteosarcoma MG-63 and osteoblast hFOB1.19 cell lines were purchased from the Type Culture Collection of Chinese Academy of Sciences (Shanghai, China). MG-63 cells were cultured in MEM/EBSS (Hyclone, Logan, UT, USA) supplemented with $10 \%$ heat-inactivated fetal bovine serum (FBS, Hyclone), $50 \mathrm{U} / \mathrm{mL}$ penicillin, and $50 \mathrm{mg} / \mathrm{mL}$ streptomycin in a humidified incubator with $5 \% \mathrm{CO}_{2}$ at $37^{\circ} \mathrm{C}$. The hFOB1.19 cells were cultured with DMEM/F12 (v/v: 1:1, Hyclone) supplemented with 10\% FBS and $0.3 \mathrm{mg} / \mathrm{mL}$ G418 (Sigma, St. Louis, MO, USA) under the same conditions.

2.2. Total RNA Extraction and HOTAIR Quantitative RealTime PCR. Total RNA was isolated and purified from MG63 and hFOB1.19 cells by the RNeasy Mini Kit (Qiagen, Inc.). And cDNA was synthesized from the total RNA by reverse transcription with PrimeScript ${ }^{\circledR}$ 1st strand cDNA Synthesis Kit (TaKaRa Bio, Shiga, Japan). Sequences of all the primers are shown in the following list (Primer Sequence for PCR). The expression of HOTAIR was quantified by fluorescencebased RT-PCR amplification.

Primer Sequence for PCR

Sequence $\left(5^{\prime}-3^{\prime}\right)$

TGF- $\beta$-Forward: $5^{\prime}$-GCTGTGAAGCCTTGAGAGTAATGG-3'

TGF- $\beta$-Reverse: $5^{\prime}$-TTCCTGTTGACTGAGTTGCGATAA- $3^{\prime}$

p53-Forward: $5^{\prime}$-TACTCCССТGCCCTCAACAAGA- $3^{\prime}$

p53-Reverse: $5^{\prime}$-CGCTATCTGAGCAGCGCTCATG-3'

TNFa-Forward: $5^{\prime}$-CCTGTCTCTTCCTACCCAACC- $3^{\prime}$

TNFa-Reverse: 5'-GCAGGAGTGTCCGTGTCTTC$3^{\prime}$
Bcl-2-Forward: $5^{\prime}$-ATGTGTGTGGAGAGCGTCAA- $3^{\prime}$

Bcl-2-Reverse: $5^{\prime}$-ACAGTTCCACAAAGGCATCC$3^{\prime}$

HOTAIR-Forward: $\quad 5$ '-GGGTGTTGGTCTGTGGAACT- $3^{\prime}$

HOTAIR-Reverse: $5^{\prime}$-CAGTGG-GGAACTCTGACTCG-3'

GAPDH-Forward: $\quad 5^{\prime}$-CTTTGGTATCGTGGAAGGACTC- $3^{\prime}$

GAPDH-Reverse: $\quad 5^{\prime}$-GTAGAGGCAGGGATGATGTTCT-3'

2.3. HOTAIR Retroviral Vector Construction and RNA Interference. To knock down HOTAIR in MG-63 cells, Knockout $^{\mathrm{TM}}$ RNAi Systems (Clontech Laboratories Inc., CA, USA) were used according to the manufacturer's protocol. Briefly, shRNA sequence targeted HOTAIR was designed and shown in Primer Sequence for PCR in Section 2.2 [20]. The complementary shRNA oligonucleotides were annealed and ligated into the pSIREN vectors (shHOTAIR). Then, Plat-A cells were transfected with shHOTAIR or PSIREN vector [21], and MG-63 cells were infected with the recombinant retroviruses and selected with puromycin. Each in vitro experiment was performed in triplicate.

2.4. Cell Proliferation Assay. $1 \times 10^{4}$ cells were seeded per well in 96 well plates in normal cell growth media. To investigate the proliferation of transfected MG-63 cells, the 3(4,5-dimethylthiazol-2-yl)-2,5-diphenyltetrazolium bromide (MTT) assay was performed using a Cell Proliferation Kit I (GE Healthcare Life Sciences, NJ) according to the manufacturer's protocol. The absorbance at $570 \mathrm{~nm}$ was determined by VersaMax (Molecular Devices, CA) to estimate MTTformazan production after 24,48 , and 72 hours of incubation to evaluate the proliferation rate. The index was evaluated at 48 and 72 hours normalized to that at 24 hours.

2.5. Apoptosis Rate Determination In Vitro. The transfected cells were fixed with $2.5 \%$ glutaraldehyde for $30 \mathrm{~min}$. Annexin V-FITC and PI staining flow cytometry was used to determine apoptosis rates by determining the relative amount of Annexin V-FITC positive and PI negative cells. Unstained cells and cells stained with Annexin V-FITC or PI alone were used as controls.

2.6. Protein Extraction and Western Blotting. The total protein was extracted from collected MG-63 cells and separated with $10 \%$ SDS-PAGE. Then the gel was transferred to a PVDF membrane (Solvay Chemicals, Belgium) and blocked for $1 \mathrm{~h}$. The rabbit anti-TGF- $\beta, \mathrm{p} 53, \mathrm{Bcl}-2$, and TNF- $\alpha$ antibody and goat anti-rabbit IgG antibody were used as primary and secondary antibody at dilution of $1: 1000$ and $1: 10000$, respectively. Signal was visualized with the ECL kit (Amersham International, Amersham, UK). Image J software (NIH, Bethesda, MD, USA) was used to compare the gray values 


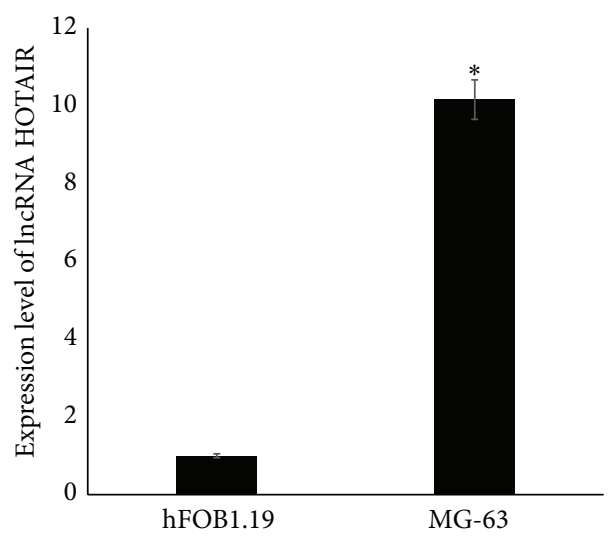

(a)

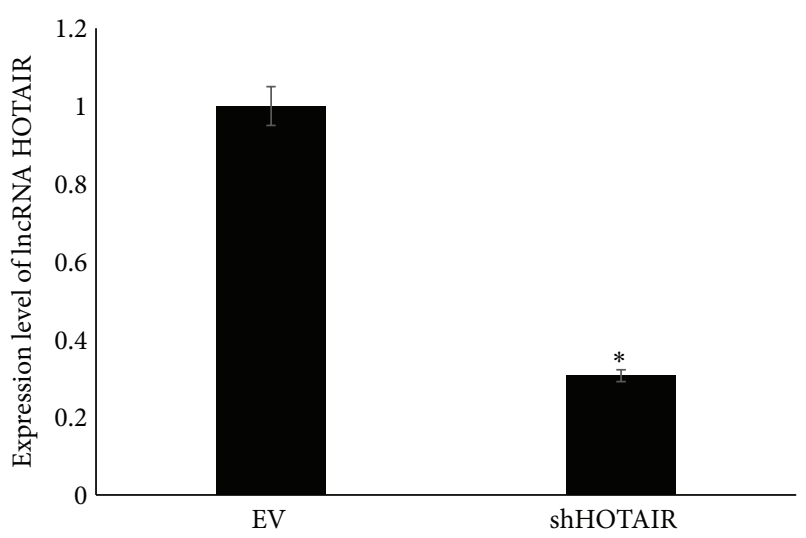

(b)

FIGURE 1: The expression level of lncRNA HOTAIR determined by RT-PCR. (a) The expression level of lncRNA HOTAIR in osteoblast cell line hFOB1.19 and osteosarcoma cell line. (b) The expression level of lncRNA HOTAIR in MG-63 transfected with empty vectors (EV) and shHOTAIR. ${ }^{*} P<0.05$.

between the proteins of interest and the internal control protein, as well as between the phosphorylated protein and the total protein.

2.7. RT-PCR Analysis. The expression levels of TGF- $\beta$, p53, Bcl-2, and TNF- $\alpha$ mRNA in transfected MG-63 cells were assessed by RT-PCR. Total RNA was extracted from cells using the Trizol method, after which cDNA was synthesized from the RNA by reverse transcription. PCR amplification was performed to allow for fluorescence-based quantitation of the gene expression. PCR reaction volumes were $10 \mu \mathrm{L}$ and composed of cDNA $(1 \mu \mathrm{L})$, primers $(0.2 \mu \mathrm{L}$ each), $2 \times$ Premix Ex Taq $(5 \mu \mathrm{L})$, and $\mathrm{H}_{2} \mathrm{O}(3.6 \mu \mathrm{L})$. The primer sequences used were listed in Primer Sequence for PCR in Section 2.2.

\section{Results}

3.1. The Differential Expression of HOTAIR in MG-63 and hFOB1.19 Cells. The expressions of lncRNA HOTAIR in human osteosarcoma MG-63 and osteoblast hFOB1.19 cell lines were estimated and shown in Figure 1(a). HOTAIR was highly expressed in osteosarcoma MG-63 cell line compared with normal osteoblast hFOB1.19 cell line. To investigate the function of HOTAIR in osteosarcoma cells, the HOTAIR was knocked down in MG-63 cells using retroviral vectors transfection. As shown in Figure 1(b), the shHOTAIR MG63 cells expressed significantly lower level of HOTAIR than that in MG-63 cells transfected with empty vectors.

3.2. The HOTAIR Was Associated with the Proliferation and Apoptosis of MG-63 Cells. The proliferation and apoptosis of MG-63 cells after transfection were determined and shown in Figures 2 and 3. The proliferation rate was lower and the apoptosis rate was higher significantly in shHOTAIR MG-63 cells than those in EV MG-63 cells. These results indicated that HOTAIR could promote the proliferation and inhibit the apoptosis of MG-63 cells as a carcinogenic lncRNA.

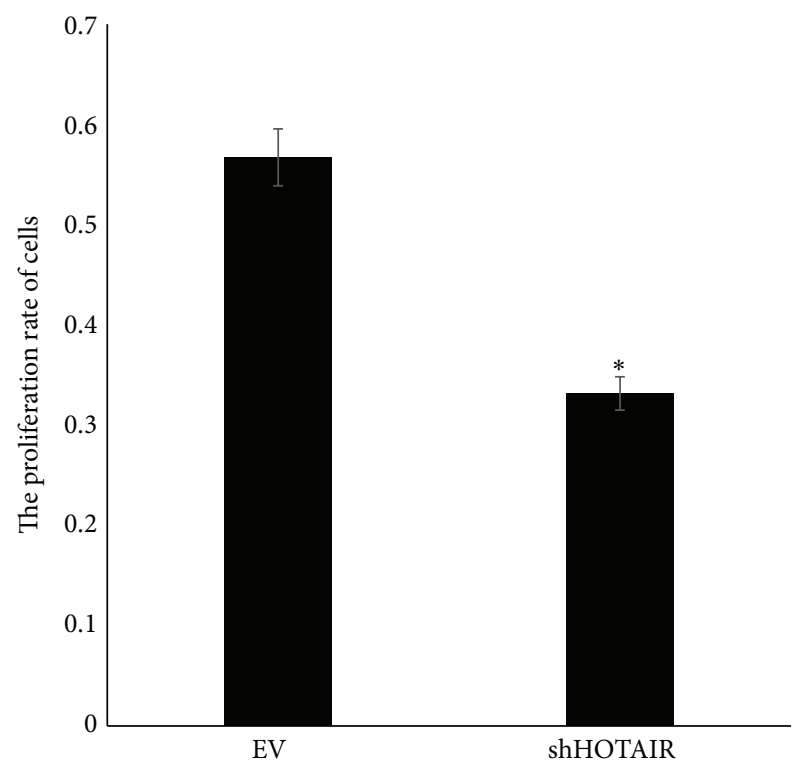

FIGURE 2: The proliferation rate of MG-63 transfected with empty vectors $(\mathrm{EV})$ and shHOTAIR. ${ }^{*} P<0.05$.

3.3. Expression Level of Tumor Related Factors. Expression levels of TGF- $\beta$, p53, Bcl-2, and TNF- $\alpha$ mRNAs and proteins in infected MG-63 cells were determined by RT-PCR and western blotting, which were shown in Figure 4. TGF- $\beta$ and Bcl-2 were downregulated significantly when HOTAIR was knocked down. p53 and TNF- $\alpha$ were upregulated significantly when HOTAIR was knocked down.

\section{Discussion}

In this study, major findings were that HOTAIR was highly expressed in OS cell line MG-63 compared with normal osteoblast cell line hFOB1.19, the proliferation rate was lower, and the apoptosis rate was higher significantly when 


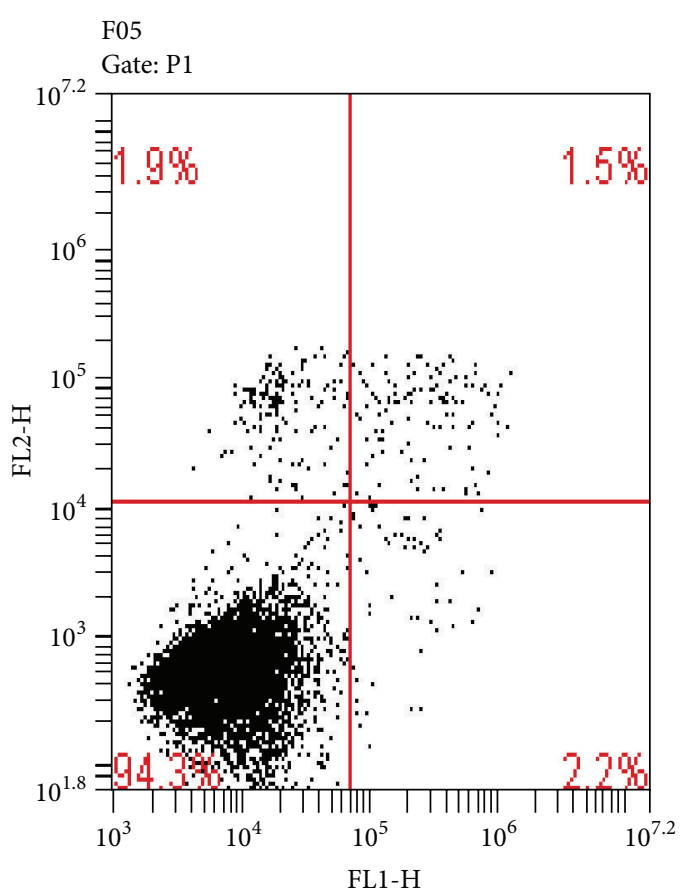

$\mathrm{EV}$

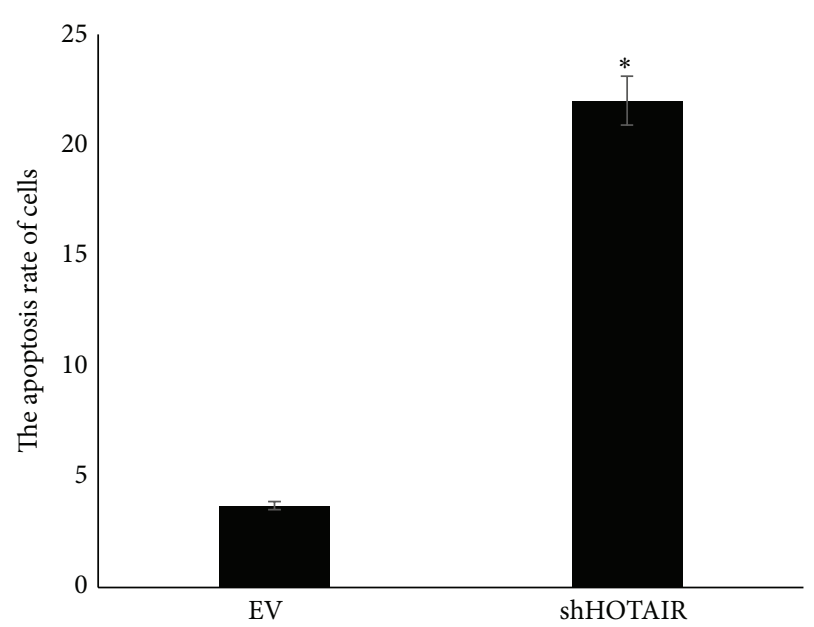

F05

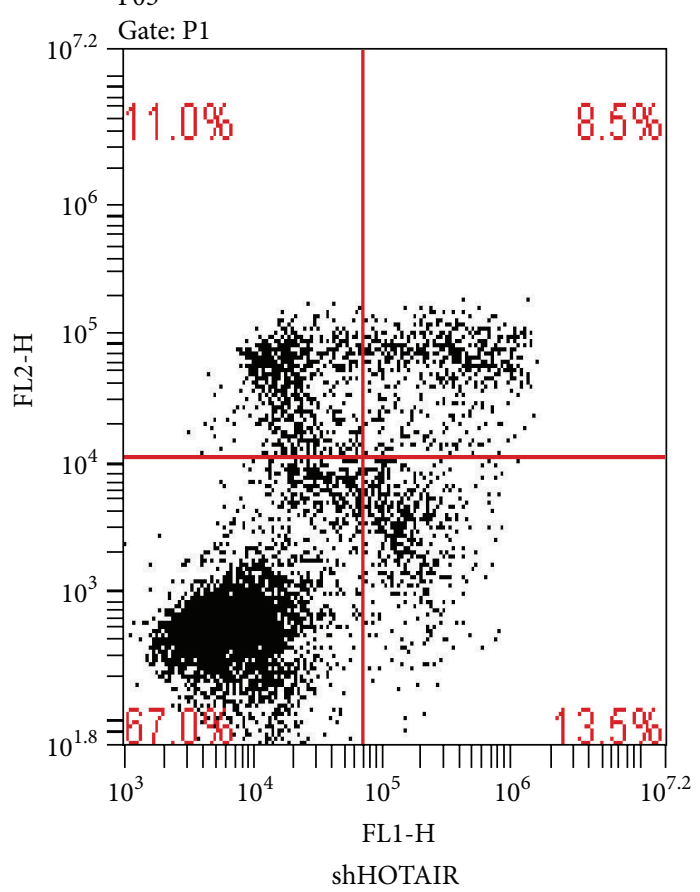

FIgURE 3: The apoptosis rate of MG-63 transfected with empty vectors (EV) and shHOTAIR. ${ }^{*} P<0.05$.

HOTAIR was knocked down in MG-63 cells, and tumor related factors TGF- $\beta$, p53, Bcl-2, and TNF- $\alpha$ were differently expressed in MG-63 cells when HOTAIR was knocked down. HOTAIR, one of the most commonly high-regulated lncRNAs in tumor cells, could promote the proliferation and inhibit the apoptosis as an oncogenic lncRNA.

lncRNAs are commonly transcribed in the genome and play critical roles in tumor progress because of their various functions in posttranscriptional, transcriptional, and epigenetic mechanisms of gene regulation. Studies have shown that lncRNAs are abnormally expressed in various cancers and play both oncogenic and tumor suppressive roles in the development of cancer [5]. For example, Steroid Receptor RNA Activator (SRA) is a potential biomarker of steroiddependent tumors and highly expressed in various cancers, including human uterus, ovary, and breast cancer [22]. Metastasis-Associated Lung Adenocarcinoma Transcript 1 (MALAT1) is widely expressed in normal human tissues [23, 24] and is upregulated in various human cancers, including breast, prostate, colon, liver, and uterus cancers [25-28]. While Growth Arrest-Specific 5 (GAS5) is a tumor suppressor lncRNA and is significantly downregulated in breast cancers, and GAS5 can induce cell apoptosis directly or indirectly in cancer cell lines [29]. HOTAIR is the first discovered tumor related lncRNA and is upregulated in breast, hepatocellular, colorectal, pancreatic, and other cancers in recent years [30-32]. Most existing studies mainly focus on the cancer metastasis, poor survival time, and poor prognosis. In our study, we first investigated the association between HOTAIR and OS and further clarified the effects of HOTAIR on the 


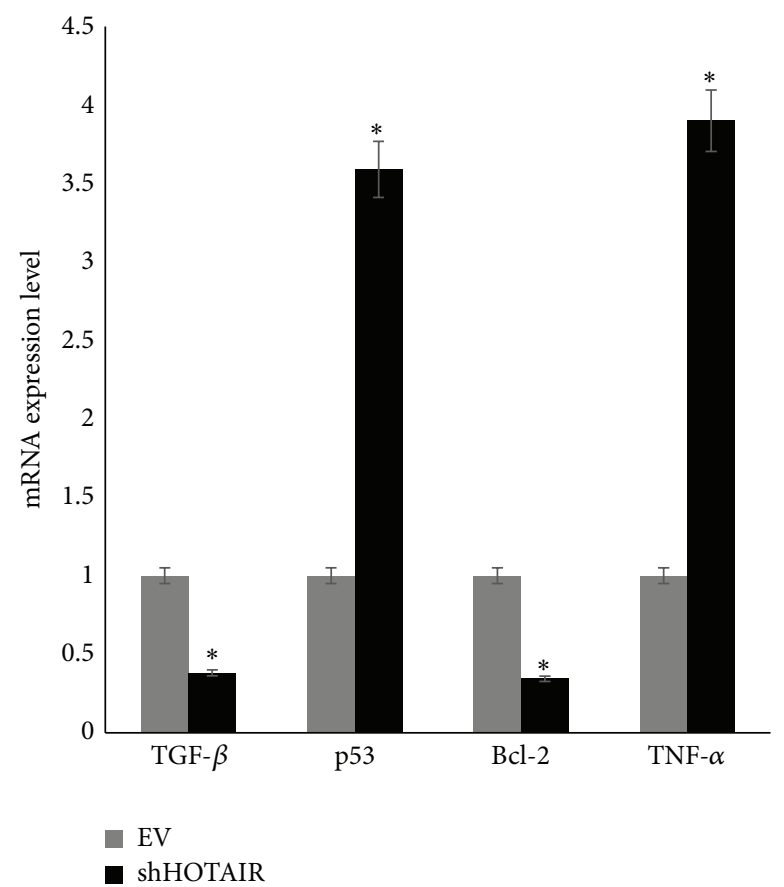

(a)

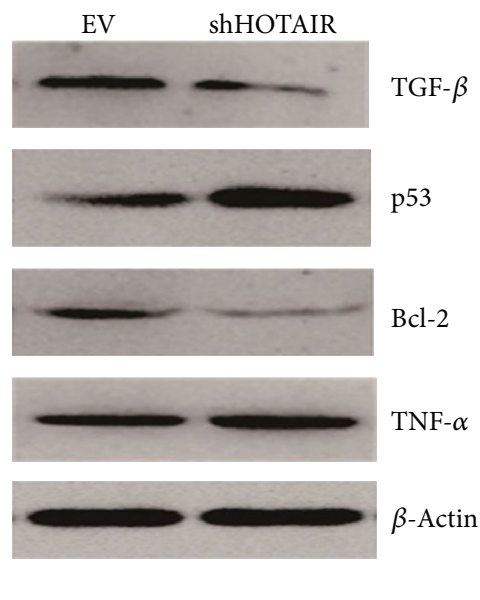

(b)

FIGURE 4: The expression level of tumor related factors in MG-63 transfected with empty vectors (EV) and shHOTAIR. (a) The expression level of mRNAs. (b) The expression level of proteins. ${ }^{*} P<0.05$.

proliferation and apoptosis of OS cells MG-63 in vitro. Similar results were obtained such that HOTAIR was upregulated in OS cells as an oncogenic lncRNA, which could promote the proliferation and inhibit the apoptosis of MG-63 cells.

p53 gene is the most prominent tumor suppressor gene encoding the cellular tumor antigen p53 (Tp53). It is a pivotal tumor suppressor that induces apoptosis and blocks cell cycle [33]. B-cell lymphoma-2 (bcl-2) is an inner mitochondrial membrane protein, which can block programmed cell death, inhibit apoptosis, and participate in the survival of cancer cells [34]. Many studies have proved that p53 can induce apoptosis through inhibiting bcl-2 proteins and they all function in the p53 pathway [35]. The p53 pathway is well studied in the context of regulating cell cycle and apoptosis, and emerging evidences in recent years suggest that several lncRNAs such as MEG3, MALAT1, LOC285194, and PANDA are involved in p53 pathway [6]. In this study, we detected the expression level of p53 and bcl-2 after silencing HOTAIR and found that the level of p53 was upregulated significantly while bcl-2 was downregulated. These results indicated that HOTAIR was associated in the p53-mediated apoptosis pathway in OS MG-63 cells. However, the direct target of HOTAIR in apoptosis pathway still needs further studies. TGF- $\beta$ is a member of TGF- $\beta$ superfamily and mainly regulates the cell growth and differentiation processes which has been reported in various cancers. In vitro and in vivo studies have shown that TGF- $\beta$ can regulate bone formation by inducing osteoblast and osteoclast proliferation [36] and high expression level was observed in osteosarcoma cells [37]. TNF- $\alpha$ is a potent cytokine produced primarily by activated macrophages and reported to inhibit the proliferation and differentiation in osteosarcoma cells in vitro [38]. In our study, TGF- $\beta$ was downregulated after silencing HOTAIR whereas TNF- $\alpha$ was upregulated in MG- 63 cells. These results indicated that HOTAIR could induce the proliferation of OS MG-63 cells although the integrated mechanism still needed further investigation.

Above all, HOTAIR is associated with the tumor tumorigenesis and development of OS and can serve as a potential treatment target clinically in future.

\section{Conclusions}

HOTAIR can promote the proliferation and inhibit the apoptosis of MG-63 cells in vitro and can be a potential target for the treatment of osteosarcoma.

\section{Competing Interests}

All authors declare no financial and nonfinancial competing interests.

\section{References}

[1] A. Jemal, R. Siegel, E. Ward, T. Murray, J. Xu, and M. J. Thun, "Cancer statistics, 2007," CA-A Cancer Journal for Clinicians, vol. 57, no. 1, pp. 43-66, 2007.

[2] P. Picci, “Osteosarcoma (Osteogenic sarcoma)," Orphanet Journal of Rare Diseases, vol. 2, article 6, 2007. 
[3] N. Jaffe, O. S. Bruland, and S. Bielack, Pediatric and Adolescent Osteosarcoma, Springer Science \& Business Media, 2010.

[4] H. J. Mankin, F. J. Hornicek, A. E. Rosenberg, D. C. Harmon, and M. C. Gebhardt, "Survival data for 648 patients with osteosarcoma treated at one institution," Clinical Orthopaedics and Related Research, vol. 429, pp. 286-291, 2004.

[5] J. E. Wilusz, H. Sunwoo, and D. L. Spector, "Long noncoding RNAs: functional surprises from the RNA world," Genes and Development, vol. 23, no. 13, pp. 1494-1504, 2009.

[6] M. Subramanian, M. F. Jones, and A. Lal, "Long non-coding RNAs embedded in the Rb and p53 pathways," Cancers, vol. 5, no. 4, pp. 1655-1675, 2013.

[7] O. Wapinski and H. Y. Chang, "Long noncoding RNAs and human disease," Trends in Cell Biology, vol. 21, no. 6, pp. 354361, 2011.

[8] A. T. Willingham, A. P. Orth, S. Batalov et al., "Molecular biology: a strategy for probing the function of noncoding RNAs finds a repressor of NFAT,' Science, vol. 309, no. 5740, pp. 15701573, 2005.

[9] L. H. Wong, K. H. Brettingham-Moore, L. Chan et al., "Centromere RNA is a key component for the assembly of nucleoproteins at the nucleolus and centromere," Genome Research, vol. 17, no. 8, pp. 1146-1160, 2007.

[10] J. T. Lee, "Lessons from X-chromosome inactivation: long ncRNA as guides and tethers to the epigenome," Genes and Development, vol. 23, no. 16, pp. 1831-1842, 2009.

[11] L. Poliseno, L. Salmena, J. Zhang, B. Carver, W. J. Haveman, and P. P. Pandolfi, "A coding-independent function of gene and pseudogene mRNAs regulates tumour biology," Nature, vol. 465, no. 7301, pp. 1033-1038, 2010.

[12] M. Esteller, "Non-coding RNAs in human disease," Nature Reviews Genetics, vol. 12, no. 12, pp. 861-874, 2011.

[13] J. Li, Z. Xuan, and C. Liu, "Long non-coding RNAs and complex human diseases," International Journal of Molecular Sciences, vol. 14, no. 9, pp. 18790-18808, 2013.

[14] J. L. Rinn, M. Kertesz, J. K. Wang et al., "Functional demarcation of active and silent chromatin domains in human HOX loci by noncoding RNAs," Cell, vol. 129, no. 7, pp. 1311-1323, 2007.

[15] H. Ono, N. Motoi, H. Nagano et al., "Long noncoding RNA HOTAIR is relevant to cellular proliferation, invasiveness, and clinical relapse in small-cell lung cancer," Cancer Medicine, vol. 3, no. 3, pp. 632-642, 2014.

[16] L. Tang, W. Zhang, B. Su, and B. Yu, "Long noncoding RNA HOTAIR is associated with motility, invasion, and metastatic potential of metastatic melanoma," BioMed Research International, vol. 2013, Article ID 251098, 7 pages, 2013.

[17] Z.-Y. Xu, Q.-M. Yu, Y.-A. Du et al., "Knockdown of long non-coding RNA HOTAIR suppresses tumor invasion and reverses epithelial-mesenchymal transition in gastric cancer," International Journal of Biological Sciences, vol. 9, no. 6, pp. 587597, 2013.

[18] J. Zhang, P. Zhang, L. Wang, H.-L. Piao, and L. Ma, "Long noncoding RNA HOTAIR in carcinogenesis and metastasis," Acta Biochimica et Biophysica Sinica, vol. 46, no. 1, pp. 1-5, 2014.

[19] B. Wang, Y. Su, Q. Yang et al., "Overexpression of long noncoding RNA HOTAIR promotes tumor growth and metastasis in human osteosarcoma," Molecules and Cells, vol. 38, no. 5, pp. 432-440, 2015.

[20] H. Endo, T. Shiroki, T. Nakagawa et al., "Enhanced expression of long non-coding RNA HOTAIR is associated with the development of gastric cancer," PLoS ONE, vol. 8, no. 10, Article ID e77070, 2013.
[21] M. A. Alejandre-Alcázar, G. Kwapiszewska, I. Reiss et al., "Hyperoxia modulates TGF- $\beta /$ BMP signaling in a mouse model of bronchopulmonary dysplasia," American Journal of Physiology_Lung Cellular and Molecular Physiology, vol. 292, no. 2, pp. L537-L549, 2007.

[22] R. B. Lanz, S. S. Chua, N. Barron, B. M. Söder, F. DeMayo, and B. W. O'Malley, "Steroid receptor RNA activator stimulates proliferation as well as apoptosis in vivo," Molecular and Cellular Biology, vol. 23, no. 20, pp. 7163-7176, 2003.

[23] P. Ji, S. Diederichs, W. Wang et al., "MALAT-1, a novel noncoding RNA, and thymosin $\beta 4$ predict metastasis and survival in early-stage non-small cell lung cancer," Oncogene, vol. 22, no. 39, pp. 8031-8041, 2003.

[24] J. N. Hutchinson, A. W. Ensminger, C. M. Clemson, C. R. Lynch, J. B. Lawrence, and A. Chess, "A screen for nuclear transcripts identifies two linked noncoding RNAs associated with SC35 splicing domains," BMC Genomics, vol. 8, article 39, 2007.

[25] A. Guffanti, M. Iacono, P. Pelucchi et al., "A transcriptional sketch of a primary human breast cancer by 454 deep sequencing," BMC Genomics, vol. 10, article 163, 2009.

[26] K. Yamada, J. Kano, H. Tsunoda et al., "Phenotypic characterization of endometrial stromal sarcoma of the uterus," Cancer Science, vol. 97, no. 2, pp. 106-112, 2006.

[27] R. Lin, S. Maeda, C. Liu, M. Karin, and T. S. Edgington, "A large noncoding RNA is a marker for murine hepatocellular carcinomas and a spectrum of human carcinomas," Oncogene, vol. 26, no. 6, pp. 851-858, 2007.

[28] J.-H. Luo, B. Ren, S. Keryanov et al., "Transcriptomic and genomic analysis of human hepatocellular carcinomas and hepatoblastomas," Hepatology, vol. 44, no. 4, pp. 1012-1024, 2006.

[29] M. Mourtada-Maarabouni, M. R. Pickard, V. L. Hedge, F. Farzaneh, and G. T. Williams, "GAS5, a non-protein-coding RNA, controls apoptosis and is downregulated in breast cancer," Oncogene, vol. 28, no. 2, pp. 195-208, 2009.

[30] Z. Yang, L. Zhou, L.-M. Wu et al., "Overexpression of long noncoding RNA HOTAIR predicts tumor recurrence in hepatocellular carcinoma patients following liver transplantation," Annals of Surgical Oncology, vol. 18, no. 5, pp. 1243-1250, 2011.

[31] R. Kogo, T. Shimamura, K. Mimori et al., "Long noncoding RNA HOTAIR regulates polycomb-dependent chromatin modification and is associated with poor prognosis in colorectal cancers," Cancer Research, vol. 71, no. 20, pp. 6320-6326, 2011.

[32] K. Kim, I. Jutooru, G. Chadalapaka et al., "HOTAIR is a negative prognostic factor and exhibits pro-oncogenic activity in pancreatic cancer," Oncogene, vol. 32, no. 13, pp. 1616-1625, 2013.

[33] J. Mercer, M. Mahmoudi, and M. Bennett, "DNA damage, p53, apoptosis and vascular disease," Mutation Research, vol. 621, no. 1-2, pp. 75-86, 2007.

[34] D. Hockenbery, G. Niñez, C. Milliman, R. D. Schreiber, and S. J. Korsmeyer, "Bcl-2 is an inner mitochondrial membrane protein that blocks programmed cell death," Nature, vol. 348, no. 6299, pp. 334-336, 1990.

[35] T. Miyashita, S. Krajewski, M. Krajewska et al., "Tumor suppressor $\mathrm{p} 53$ is a regulator of bcl-2 and bax gene expression in vitro and in vivo," Oncogene, vol. 9, no. 6, pp. 1799-1805, 1994.

[36] L. F. Bonewald and G. R. Mundy, "Role of transforming growth factor-beta in bone remodeling," Clinical Orthopaedics and Related Research, no. 250, pp. 261-276, 1990. 
[37] P. Kloen, M. C. Gebhardt, A. Perez-Atayde et al., "Expression of transforming growth factor- $\beta$ (TGF- $\beta$ ) isoforms in osteosarcomas: TGF- $\beta 3$ is related to disease progression," Cancer, vol. 80 , no. 12, pp. 2230-2239, 1997.

[38] T. Mori, Y. Sato, K. Miyamoto et al., “TNF $\alpha$ promotes osteosarcoma progression by maintaining tumor cells in an undifferentiated state," Oncogene, vol. 33, no. 33, pp. 4236-4241, 2014. 


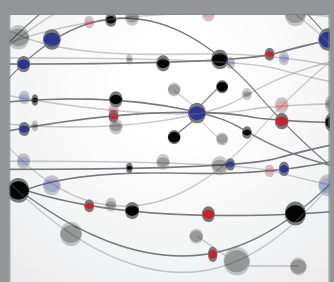

The Scientific World Journal
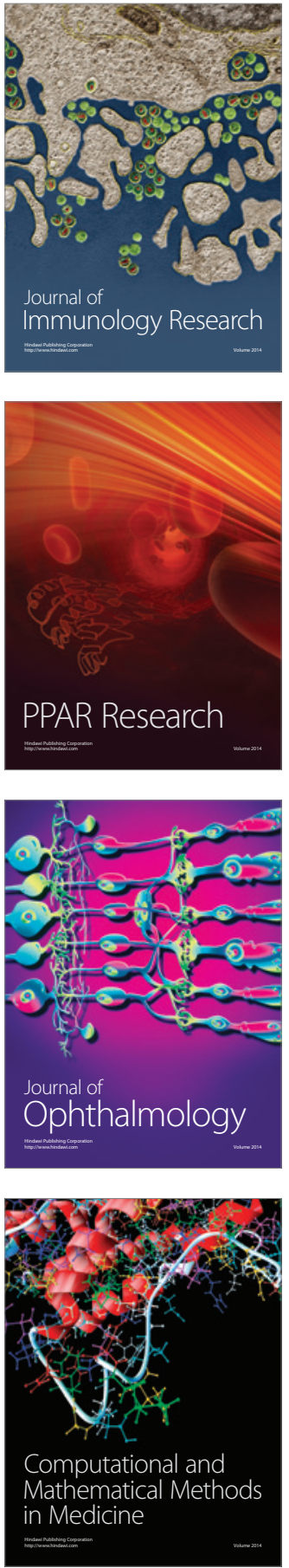

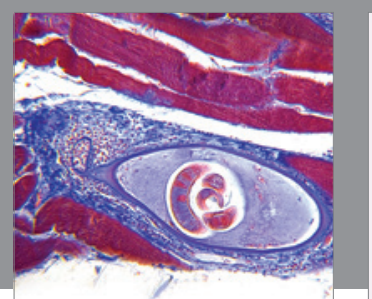

Gastroenterology Research and Practice

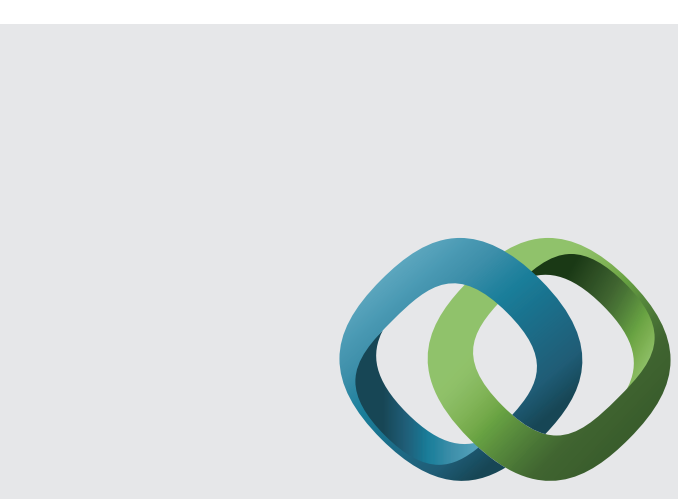

\section{Hindawi}

Submit your manuscripts at

http://www.hindawi.com
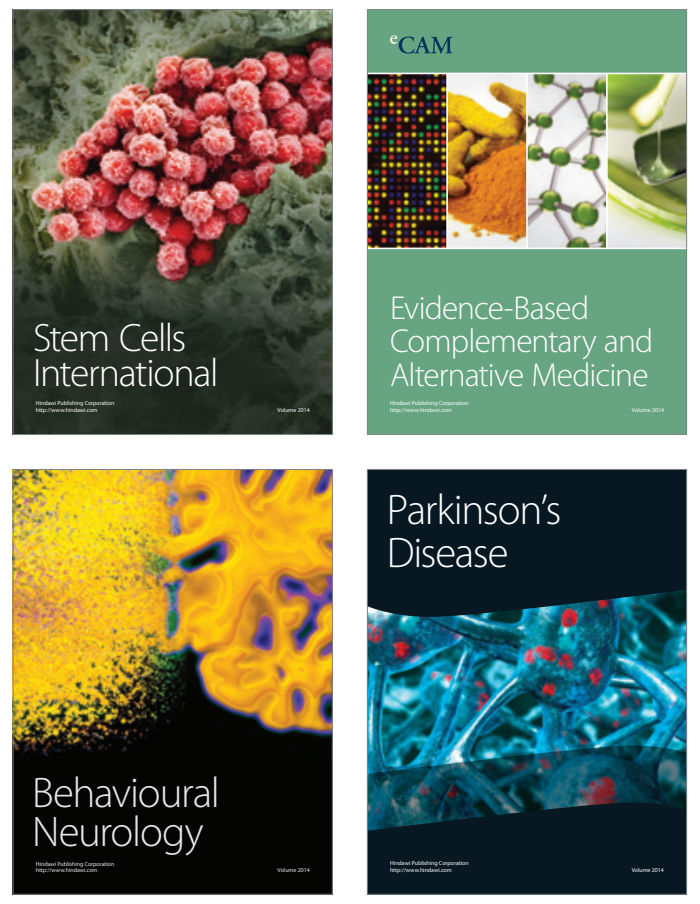
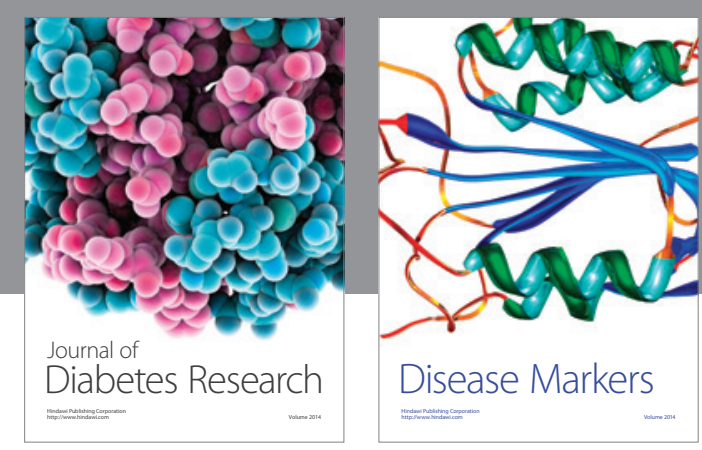

Disease Markers
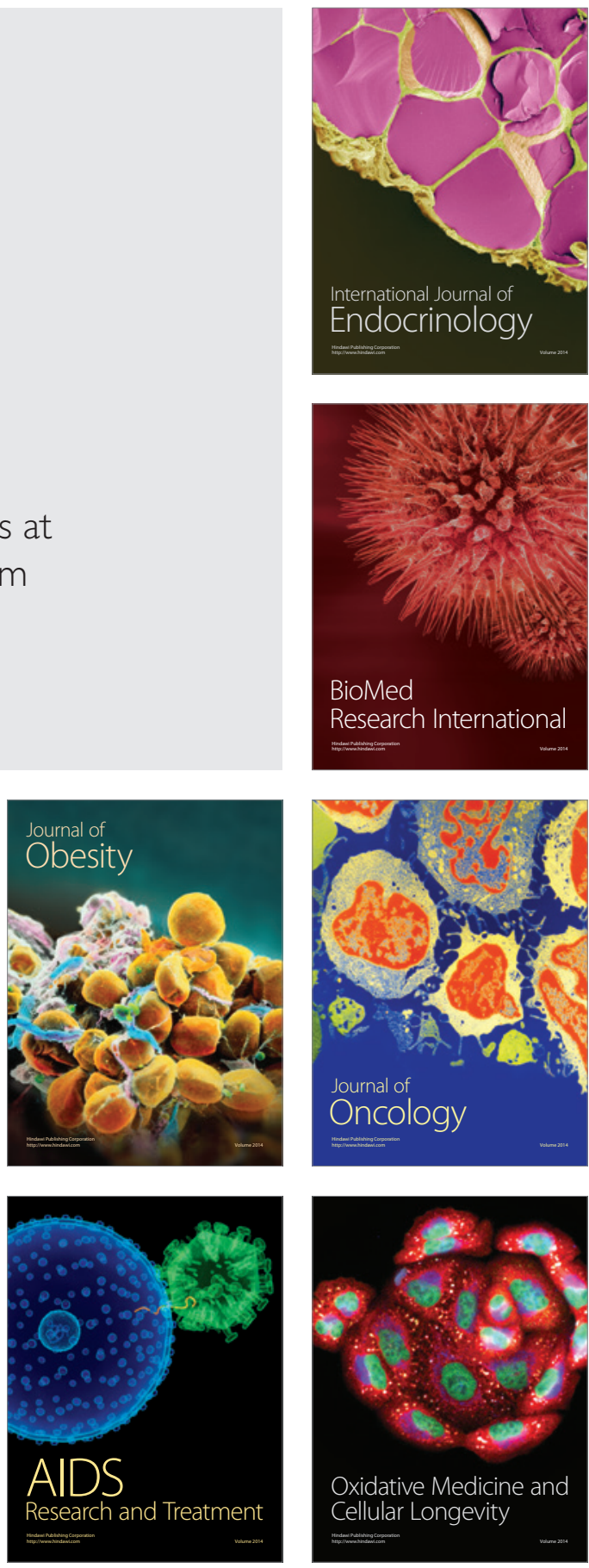